\title{
Review on Machine Learning Techniques to predict Bipolar Disorder
}

\author{
$<$ Nisha Agnihotri $>$, $<$ Sanjeev Kumar Prasad $>^{2}$ \\ ${ }^{1}$ Research Scholar, Galgotias University, nishaagnihotri31@gmail.com) \\ ${ }^{2}$ Guide, Galgotias University, sanjeevkps2002@gmail.com)
}

\begin{abstract}
:
Bipolar disorder, a complex disorder in brain has affected many millions of people around the world. This brain disorder is identified by the occurrence of the oscillations of the patient's changing mood. The mood swing between two states i.e. depression and mania. This is a result of different psychological and physical features. A set of psycholinguistic features like behavioral changes, mood swings and mental illness are observed to provide feedback on health and wellness. The study is an objective measure of identifying the stress level of human brain that could improve the harmful effects associated with it considerably. In the paper, we present the study prediction of symptoms and behavior of a commonly known mental health illness, bipolar disorder using Machine Learning Techniques. Therefore, we extracted data from articles and research papers were studied and analyzed by using statistical analysis tools and machine learning (ML) techniques. Data is visualized to extractand communicate meaningful information from complex datasets on predicting and optimizing various day to day analyses. The study also includes the various research papers having machine Learning algorithms and different classifiers like Decision Trees, Random Forest, Support Vector Machine, Nä̈ve Bayes, Logistic Regression and K- Nearest Neighbor are studied and analyzed for identifying the mental state in a target group. The purpose of the paper is mainly to explore the challenges, adequacy and limitations in detecting the mental health condition using Machine Learning Techniques.
\end{abstract}

Keywords: Big data, Machine Learning, Mood disorder, Anxiety Depression, Artificial Intelligence, python.

\section{Introduction}

World Health Organization WHO implies, a person having healthy mind and physical fitness is a healthy person. Any changes in thought process and mental health are some of the age related process and changes across the world. Depression and anxiety are mental health disorder associated with unhealthy mind. As the age increases, the consequences and vulnerability associated with depression and anxiety also increases [3]. The development and advances in big data Analytics and Technology results in more attention in prediction of disease. Various studies and researches on large number of dataset has been conducted automatically to improve the accuracy of risk classification instead of selected characteristics previously [1]. Patients having bipolar disorder significantly experiences day-today and week-to- week swings in mood. This instability in mood increases the relapse of disease and reoccurrence of risk with time, this indicates that the disease is still active. The purpose of monitoring and symptom prediction of disorder is to investigate and correlate the symptoms of disorder [8].

Machine Learning Techniques are increasingly present in almost all systems that Process and gather bulk amounts of data. The field of medicine is largelybenefited by Machine Learning. Machine Learning algorithms design the regression and classification models that help in different disease diagnosis, drug recommendation, drug administration and so on. ML is the process of creating certain models and algorithms to predict values based on different features[13]. This review paper analysis ML technique for bipolar disorder and clinical procedures. The Data of healthy and unhealthy person are reviewed from a certain survey to apply prediction algorithm.

\section{Categories of Bipolar Disorder}

Bipolar disorder is a lifelong mental illness that occurs due to episodes of Mania and depression. Even after getting treatment for the illness people continues to have symptoms for it. Each type of disorder is identified and treated differently depending upon the type of disorder as shown in Fig 1.

- Bipolar I Disorder: This disorder has symptoms of mood episodes from Mania to Depression periodically. The disorder can be diagnosed if manic episodes are seen for at least seven days followed by psychotic features. To prevent harm to the patient and others immediate hospitalization is recommended. Sometimes people have depressive episodes along with manic features for two or more weeks.

- Bipolar II disorder: In this mood elevation of milder hypomania episodes occurs alternatively with severe depression. The Common symptoms of major depressive episodes include hypersomnia, 
uncontrollable and unexplained crying, severe fatigue, Loss of interest in liveliness, thoughts of suicide and death.

- Cyclothymic disorder: These disorders have symptoms of brief periods of hypomanic episodes along with depressive symptoms. They are not long lasting and extensive in hypomanic and depressive episodes. It is a milder form of bipolar disorder consists of cycling mood swings. The symptoms usually develop in adolescence. The person suffering from cyclothymic often appears to be functionally normal and do not seek treatment. But if left untreated, cyclothymic increases risk of severe disorder.

- Mixed Features: This refers to the combined symptoms of hypomania, depression and mania. The symptoms include sleeplessness, high energy and racing thoughts. The person also feels helpless, depressing and irritated. She/he has thoughts of suicide.

- $\quad$ Rapid cycling: It is described as having different types of mood episodes in 12-month period. In this people experiences high or low mood swing polarities within a week, in the course of illness. It is more likely to be seen in women rather than men. Rapid cycling have increased patterns of severe depression and suicide attempts.

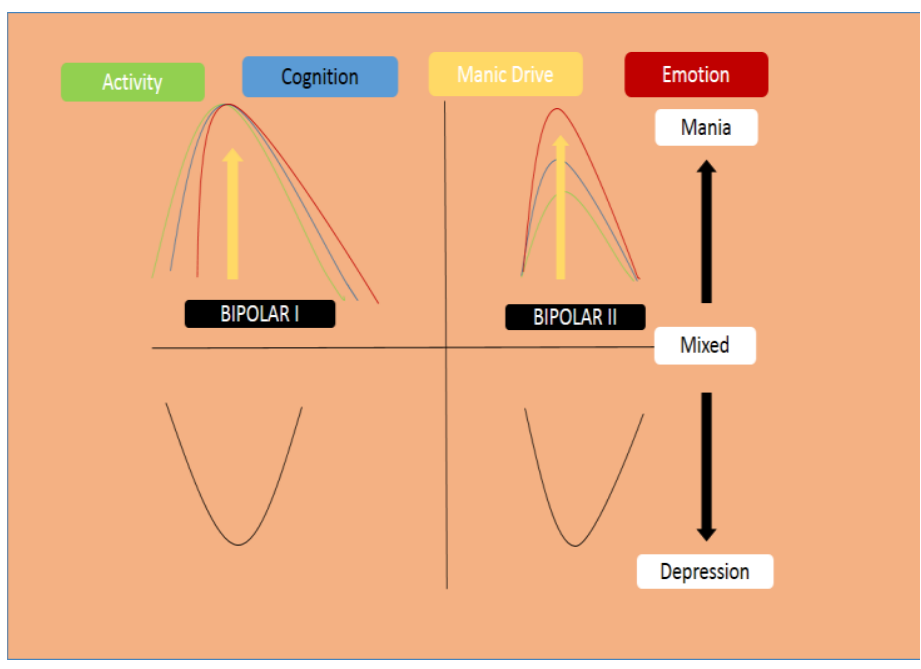

Fig. 1 Diagram to show different types of disorders

Many times the question arises that it is clinically useful to distinguish Bipolar I and II in diagnosis or not. On the other hand it there are some examples in which these disorders are merged into one broader dimensional category. For Example, the merging of Autism and Asperger's syndrome in DSM-\% into Autism Spectrum Syndrome ASD [32]. The Advantages of merging and distinction can be summarized in Table 1 .

Table 1: Advantages of Merging and distinction in Bipolar I and II disorder

\begin{tabular}{|l|l|}
\hline \multicolumn{2}{|c|}{ Advantages of Merging and distinction in Bipolar I and II disorder } \\
\hline $\begin{array}{l}\text { Advantages of merging bipolar I and II } \\
\text { disorder }\end{array}$ & $\begin{array}{l}\text { Advantages of maintaining distinction in Bipolar I and } \\
\text { II Disorder }\end{array}$ \\
\hline $\begin{array}{l}\text { It confirms for clinical dimensions by } \\
\text { a true reflection of illness to } \\
\text { clinicians. }\end{array}$ & $\begin{array}{l}\text { Maintain Consistency with lack of evidence to } \\
\text { support change }\end{array}$ \\
$\begin{array}{l}\text { This promotes greater consistency in } \\
\text { treatment approaches. }\end{array}$ & - Fewer disturbances to family and patients. \\
$\begin{array}{l}\text { It encourages more coherence in } \\
\text { bipolar thinking spectrum and } \\
\text { research }\end{array}$ & - Acknowledges differences in clinical \\
It accommodates mixed states and \\
$\begin{array}{l}\text { allows for differential clinical } \\
\text { expression of bipolar disorder. }\end{array}$ \\
\end{tabular}

\section{Machine Learning Techniques for predicting Bipolar Disorder}

Machine learning methodology, gives a comprehensive and concise analysis of how machine learning techniques can help to detect the symptoms of people suffering from Bipolar Disorder. This also focuses on predicting the 
symptoms of mental states of patients that provides a valuable insight for clinicians, patients, and researchers in reducing and preventing extreme mania and depression. The ML techniques have the following data processing steps asshown in Fig. 2. This includes planning and background Analysis, Data Acquisition, Data Analysis, Implementing Data Mining process and Performance Analysis.

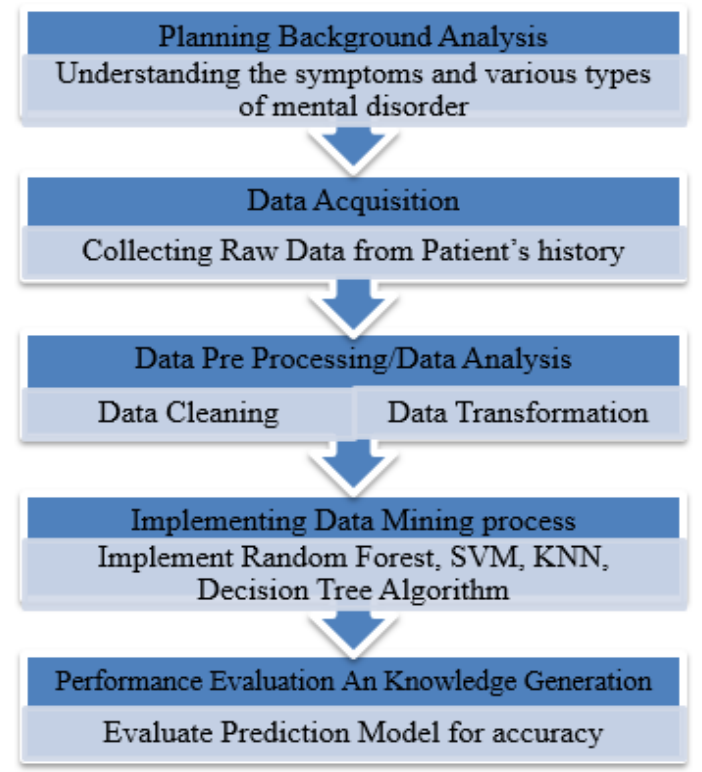

Figure 2: Machine Learning Data processing steps

\section{(3.1). Planning and Background}

Analysis: In this phase all the information regarding the individual and his illness is gathered which includes various qualitative factors like personal information, demographic information, sociodemographiccharacteristics, their Symptoms, and disease. Age, gender, their past history, chronic medical conditions, family status and environment, marital status, job security etc. are analyzed for detecting mental condition like depression and anxiety in older people [3]. These attributes are used as predictors in automated system for disease prediction [3].

\section{(3.2). Data Collection or Data}

Acquisition: Data is collected through various sources for both healthy and depressive peoples. They are analyzed forvarious parameters to detect anxiety, depression and other mental disorders. For this data is collected through various sources like surveys, questionnaires and various social media platforms. [13] Some of these sources are discussed below: -

(3.2.1)For conducting surveys related to mental health and well-being, Questionnaires were conducted from Various recognized organizations and institutions like WHO (World health organization). For example, a perceived stress scale questionnaire conducted having a subset of features. These features include heart rate, Respiration frequency, Skin conduction level, Skin conduction response rate etc. These features might react with stress and provide a better and accurate response as a result [18].

(3.2.2) The review uses Facebook user's comments for depressive behavioral exploration and detection which is a great source of data. [13]

(3.2.3) To collect psychological data, a Q-sensor anda Motion Logger in two wrist wearing sensors were used The recorded data was Skin Conduction, Temperature, Ambient light, 3- axis acceleration. The data recorded was used to monitor the daily sleep and wake patterns, activity level to give a stress index for further analysis.

(3.2.4) For analyzing social interaction, a mobile app was used. This monitors the call timings and messages, location and app usage. [7].

(3.2.5) To record audio and physical activity, a smart phone is used. This consist of few categories walking, running, stationary, and sound related categories like silence, voice, noise and unknown respectively. The starting and ending of call conversations, phone lock and GPS coordinates were recorded. [8].

\section{(3.3). Data Preprocessing- Feature Selection:}

The raw data collected in data collection phase is preprocessed in an understandable format by two methods, namely data cleaning and data transformation. This is used to differentiate the various behaviors of the patients and to select the feature on the basis of which medical assistance is given. For describing and demonstrating depressive and non-depressive comments and posts, different features were extracted from user's post having psycholinguistic features.

(3.3.1)Data Cleaning: - Data cleaning is required to remove the irrelevant data in patient prescription. For this reviewer used Linguistic inquiry and word count as a package of Psychological vocabulary. For this different intellectual, etymological and affective parts of user written and verbal correspondence are perceived.

(3.3.2)Data Transformation: - Data collected was transformed into an understandable format for implementation purpose. All null data is removed and dataset is checked for namingconvention.

\section{(3.4). Classification - Implementation and Data Mining Process: The research}


objective is to examine classification algorithm for mental health prediction. For the study, Grünerbl et al., [6] analyze around 466 mental disorder patient's dataset conclude the relation between disease diagnosis and attributes by applying machine-learning techniques. These techniques include Random forest, SVM, Knearest neighbor and decision Tree. The study compares the performances of the various algorithms using measures of accuracy to detect mental health problems. The popularalgorithms are [P6]

\section{(3.4.1) Random Forest}

This classifier is a supervised classification method also known as ensemble classification method. The result of individual prediction is averaged out using predictor attributes. They are trained by bagging method that consists of random sample subsets. By sampling the training data, the method fits a decision for each tree and aggregate the result. Many base classifiers are provided by Random Forest. Values are inputted randomly in each tree and their distribution isequal in each tree. [20].

\section{(3.4.2) Support Vector Machines (SVM)}

This classifier is a linear and non-probabilistic binary classifier used to classify data for anomaly detection. Among other ML Techniques this modal is very popular as well as costly to compute [21]. SVM is used for reducing noisy data for good results and is able to make decisions [22]. This classifier is a Statistical model used for regression challenges and classification. SVM is a supervised Machine Learning Algorithm in which for $n$ number of parameters, each $n$ parameters are plotted in n-dimensional space and assigned a specific coordinate. The classifier built a hyper plane into high dimensional feature space to isolates data in two classes. This finds a hyper plane for the purpose to separate close training datasets. SVM creates hyper plane by calculating the best possible margin (which is the difference between hyper plane and support vectors). Support vector divides dataset in higher $\mathrm{n}$ dimensional space.

(3.4.3) k-nearest neighbor ( $\mathrm{KNN})$ : $\mathrm{KNN}$ is one of the non-parameter algorithms. This captures all the training data information. Data is plotted in $\mathrm{n}$ dimension based on similarities. In a sample Test, this algorithm plots the same $\mathrm{n}$ dimensions as training data in sample. It searches for best neighbors for the value of $\mathrm{k}$. It uses to find the distances in dataset from point of interest to pointsin training dataset.

(3.4.4) Decision Tree: This is a simple and popularly used classifier based on systematic approach. Thismakes the hierarchical tree from the training dataset. The states of decision tree are to divide the hierarchy of data having different characteristics. For example, in text documents classification, roots are mainly identified in terms and internal individual nodes are subdivided into its children inview of the yes or no of a term in Ensemble. Ensemble methods use multiple learning algorithms of decision tree for better predictive performance.

\section{(3.5) Prediction - Evaluation of Performance \& Knowledge Generation:}

(3.5.1)Precision, is a measure of fraction of positive predictions in data mining, that are actually positive. Higher precision implies, that this model is better to identify the needy people for help. In This stage, a prediction model is constructed for identifying healthy and unhealthy persons by considering the psycholinguistic features as input.

(3.5.2)For example, if we take into consideration some of $\mathrm{n}$ depressive posts/comments in the model, so that each post/comments is highlighted or labeled either as depressive or non-depressive post/comment. The task with respect to classifier is to find the corresponding label for each posts/comments.

(3.5.3)Lastly, the outcomes or result are calculated. For better performance, the attributes or parameters of different algorithms are takeninto consideration and compared with each other. The model which gives most accurate result is evaluated and used for prediction.

\section{Investigating ML techniques for the prediction of Bipolar disorder}

The review aims to study and give a clear and concise literature investigating Machine Learning ML techniques for the prediction of Bipolar disorder. The literature review aims to reduce the occurrence and prevalence of the anxiety disorders by effective early prediction. This results in significant minimization of hospitalization, improving their quality of life and reduces their health care bills to a large extent. The Literature review has three stages as shown in Fig 3.

- During the first stage, we reviewed 125 papers related to health issues and ML techniques through selected datasets like springer, IEEE, Research gate etc. Additionally, we referred 25 articles from different sources. Out of which 31 papers are related to mental health illness or disorders and machine learning are studied and reviewed by their abstracts and titles.

- During second stage, 12 articles as mentionedin Table-2, are directly related to prediction of 
mental health disorder and their prediction using Machine Learning Techniques are reviewed. These are reviewed thoroughly in full text mode and their reference list is referred for related extra studies.

- During the third stage, thorough examination of the related literature and included studies is involved. Input data and measurement methods are used as tools for acquiring essential information. This information is drawn to conclude accuracy and to draw a conclusion.

Different related studies are recently carried out in this area of mental health disorder and crisis prediction. This is indeed, a new and emerging area of research to apply a prediction algorithm. Studies related to this area in which researchers attempted to predict symptoms in patients having Bipolar Disorder.

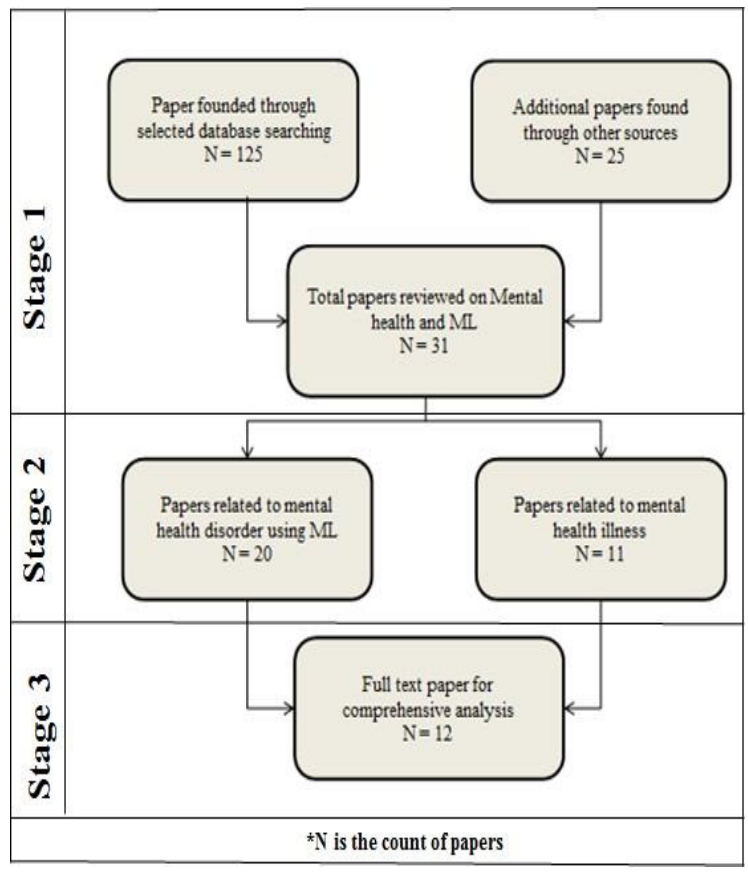

Fig 3: Flow Diagram of Machine Learning processing

Vinitha S et al. [1] studies a ML decision tree map algorithm by using structured data and unstructured data from hospital for portioning of data. It reaches a $94.8 \%$ quicker speed to produce report consist of possibilities of occurrence of disease. Axel Junestrand Leal. [2] implemented a Machine Learning Techniques to develop a prediction model by using symptom based data of patients. The papers [3] and

[20] aim to diagnose anxiety and depression behaviorin old age persons by studying their socio demographics and other health related factors using Machine Learning Techniques. A. Grünerbl. [4], Grünerbl et al., [6] and J. Nicholas et al. [7] With the technologies predict changes in bipolar disorder patients by classification of depressive and manic state of patient using sensors in smartphones. Doryab et al. [5] By applying Machine Learning Techniques he investigated which are the important features in health related issues based on ranking features. Grof et al. [9] prepared mood charting for monitoring the patients and to give the appropriate understand of mental health conditions by observing their daily routine chart that represent their state of mood. M. Faurholt-Jepsen et al. [8] studied symptoms of bipolar disorder by gathering objective data from smartphones. For this patient have to write their physical and social activities daily in the evening for a period of time. Akshi Kumara et al. [10] in this a AD novel prediction model is proposed for prediction of anxious depression in real time tweets. This studies the mixed disorder od anxiety and depression associated with thought process, lack of sleep and restlessness. Ezekiel Victor et al. [11] suggested a methodology which evaluates ML techniques for detecting depression that require minimal human intervention.in terms of data collection and data labeling. Emmanuel $\mathrm{G}$ et al. [12], Conducted a comparative literature search using ML Techniques to predict specific types of stress and anxiety disorder and to develop certain tools that assists doctors in prediction of mental health and support in caring patients. Md. Rafiqul Islam et al [13] implements ML techniques to identify and implement a quality solution for mental disorder problem bystudying Social media users comments and posts specially Facebook users. For this they monitor their attributes, feeling and behavior. Their mood swing patterns while they communicate with other user in online communications. Adrian B. R. Shatte et al. [14] according to this paper there is scope of Machine Learning in the area of Psychology and Mental Health, and evidently focus on prediction and diagnosis of mental health condition. Liana C.L.et al. [15] Their study and findings gives an early neuroimaging techniques for clinical assessment in young adults irrespective of objective and qualitative estimation of Psychopathology. Alicia Martinez et al. [16] Abd Rehman et al. [22] This paper aims at providing a guideline for further research in the direction of health care prediction system using Machine Learning Techniques. The electronic dataset on health records Provides a valuable information about the health risk and its predictions. The ML applications and methodshas provided benefits in treatment, support and diagnosis of research and clinical administration. A. Khatter et al. [23], how to deal with pandemic situations and save lives in Lockdown. Students adjusted them well at their homes with restrictions and with a that one day their life will again be normal as before. They cope up with online teaching Learning method, online exam patterns, admissions to higher studies and summer internships etc. MS. Purude Vaishali Narayanrao et al. [25], include different approaches to predict heart attack, peer pressure and

depression. The data collection mechanism includes questionnaires and surveys with different people, theirsocial media posts, text messages and 
verbal communication and facial expressions. Ela Gore et al.

[26] aim of the paper is to present commonly used algorithms and methods to describe the performance that act as a guide in selection of appropriate model. The alternates and possibilities of ML helps to bridgethe gap between psychiatrist and patients to reveal theembarrassment of patient in critical shortfalls. Norah Saleh Alghamdi [28] study the use and benefits of Artificial intelligent application which uses text analytical tool for mental health support. This app uses different technologies and innovative sensors built in smart devices. By using camera sensors and performing self testing scales it detects anxiety and depression. U Srinivas ulu Reddy et al. [29] by applying ML Techniques, a stress analysis pattern is studied in working employees and to narrow down thestress levels. For the study they used 2017 mental health survey that includes responses of technologies working employees. Vidhi Mody Pruthi Mody [30] facilitates a specialized care and emotional support formental health people with the help of Machine Learning algorithms and Advanced Artificial Intelligence Techniques. Shahidul Islam Khan et al. [31] The study examines a classification algorithm thatis used to predict mental health disorder.

Table-2 - Studies related to dataset classifiers and ML Approaches.

\begin{tabular}{|c|c|c|c|c|c|}
\hline Aim of the Paper & Authors & ML Approach & Data Source & $\begin{array}{l}\text { Mental } \\
\text { Health Type }\end{array}$ & Keywords \\
\hline $\begin{array}{lrr}\text { Effects } & \text { of } & \text { the } \\
\text { Disastrous Pandemic } \\
\text { COVID } 19 \text { on } \\
\text { Learning } & \text { Styles, } \\
\text { Activities } & \text { and } \\
\text { Mental Health of } & \text { Houng } & \text { Indian } \\
\text { Young } & \text { A } \\
\text { Students } & -\quad \text { A } \\
\text { Machine } & \text { Learning } \\
\text { Approach } & (2020)\end{array}$ & $\begin{array}{l}\text { Anuradha } \\
\text { Khattar } \\
\text { al..[23] }\end{array}$ & $\begin{array}{l}\mathrm{R} \text { and Python for } \\
\text { Visualization, MS- } \\
\text { Excel }\end{array}$ & $\begin{array}{l}\text { Questionnaires and } \\
\text { survey }\end{array}$ & Stress & $\begin{array}{l}\text { Online Teaching } \\
\text { and Learning, } \\
\text { Pandemic, } \\
\text { COVID-19, } \\
\text { Mental health, } \\
\text { social life. }\end{array}$ \\
\hline $\begin{array}{l}\text { Analysis of Machine } \\
\text { Learning Algorithms } \\
\text { for Predicting } \\
\text { Depression }\end{array}$ & $\begin{array}{l}\text { MS. Purude } \\
\text { Vaishali et } \\
\text { al.[25] }\end{array}$ & $\begin{array}{l}\text { Feature dynamic } \\
\text { history histogram } \\
\text { (FDHH, PLS \& } \\
\text { LR, SVM }\end{array}$ & $\begin{array}{l}\text { Social media posts, } \\
\text { questionnaires, } \\
\text { verbal } \\
\text { Communication, } \\
\text { facial expression. }\end{array}$ & Depression & $\begin{array}{lr}\begin{array}{lr}\text { ML, } \\
\text { health }\end{array} & \text { andal } \\
\text { predictive } & \\
\text { analysis } & \end{array}$ \\
\hline $\begin{array}{l}\text { The Identification } \\
\text { research of bipolar } \\
\text { disorder based on } \\
\text { CNN }\end{array}$ & $\begin{array}{l}\text { Qiu Sun et al. } \\
{[20]}\end{array}$ & $\mathrm{CNN}$ & Samples and SNP & $\begin{array}{l}\text { Bipolar } \\
\text { Disorder }\end{array}$ & $\begin{array}{l}\text { Bipolar disorder, } \\
\text { big data }\end{array}$ \\
\hline $\begin{array}{l}\text { Mental Disorder } \\
\text { Detection: Bipolar } \\
\text { Disorder } \\
\text { Scrutinization Using } \\
\text { Machine Learning }\end{array}$ & $\begin{array}{l}\text { Ranjana Jadhav } \\
\text { et al. } \\
{[20]}\end{array}$ & SVM,Decision Tree & Questionnaire & $\begin{array}{l}\text { Bipolar } \\
\text { Disorder }\end{array}$ & $\begin{array}{l}\text { ML, MDQ, Mood } \\
\text { disorder, Bipolar } \\
\text { disorder }\end{array}$ \\
\hline $\begin{array}{l}\text { Machine learning in } \\
\text { mental health: } \\
\text { A systematic } \\
\text { scoping review of } \\
\text { methods and } \\
\text { applications }\end{array}$ & 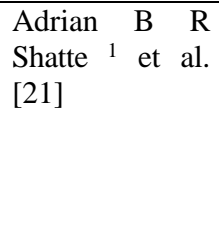 & $\begin{array}{l}\text { SVM, Decision Tree, } \\
\text { unsupervised }(\mathrm{KNN})\end{array}$ & $\begin{array}{ll}\text { Survey } & \text { and } \\
\text { questionnaire } & \end{array}$ & $\begin{array}{l}\text { Anxiety and } \\
\text { depression }\end{array}$ & $\begin{array}{l}\text { Big data ML, } \\
\text { Mental health, } \\
\text { health informatics }\end{array}$ \\
\hline $\begin{array}{lr}\text { Surveying } & \text { Machine } \\
\text { Learning algorithms } \\
\text { on }\end{array}$ & $\begin{array}{l}\text { Ela Gore et al. } \\
{[25]}\end{array}$ & EEG signal & $\begin{array}{l}\text { EEG Signal Data } \\
\text { and male, female } \\
\text { participants }\end{array}$ & Depression & $\begin{array}{l}\text { EEG Signals, } \\
\text { ML, SVN, CNN }\end{array}$ \\
\hline
\end{tabular}




\begin{tabular}{|c|c|c|c|c|c|}
\hline $\begin{array}{l}\text { Monitoring Mental } \\
\text { Health Using Smart } \\
\text { Devices with Text } \\
\text { Analytical Tool }\end{array}$ & $\begin{array}{l}\text { Norah Saleh } \\
\text { Alghamdi } \\
{[27]}\end{array}$ & SVM & $\begin{array}{l}\text { Using sensor, text } \\
\text { analyting tools }\end{array}$ & $\begin{array}{l}\text { Anxiety and } \\
\text { depression }\end{array}$ & $\begin{array}{l}\text { Anxiety, } \\
\text { Depression, } \\
\text { Classification } \\
\text { modal, Text } \\
\text { Analysis and } \\
\text { device prediction } \\
\text { by ML }\end{array}$ \\
\hline $\begin{array}{lr}\text { Mental } & \text { Health } \\
\text { Monitoring } & \text { System } \\
\text { using } & \text { Artificial } \\
\text { Intelligence: } & \text { A } \\
\text { Review } & \end{array}$ & $\begin{array}{l}\text { Vidhi Mody, } \\
\text { Vrushti Mody } \\
{[29]}\end{array}$ & $\begin{array}{l}\text { RBF Kernel \& SVM } \\
\text { Model }\end{array}$ & $\begin{array}{lr}\text { From } & \text { Smartphones } \\
\text { and } & \text { wearable } \\
\text { devices } & \end{array}$ & $\begin{array}{l}\text { Anxiety and } \\
\text { depression }\end{array}$ & $\begin{array}{l}\text { AI, ML, Expert } \\
\text { System, Virtual } \\
\text { Counselling, } \\
\text { Precision } \\
\text { Therapy }\end{array}$ \\
\hline $\begin{array}{l}\text { Machine Learning } \\
\text { Techniques for } \\
\text { Stress Prediction in } \\
\text { Working Employees }\end{array}$ & $\begin{array}{l}\text { U Srinivasulu } \\
\text { Reddy et } \\
\text { al.[28] }\end{array}$ & $\begin{array}{lr}\text { Random } & \text { Forest, } \\
\text { SVM, KNN, Decision } \\
\text { Tree, } & \text { Bagging, } \\
\text { Boosting } & \end{array}$ & $\begin{array}{lr}\text { Survey } & \text { and } \\
\text { responses } & \text { of } \\
\text { Employees } & \end{array}$ & Stress & $\begin{array}{l}\text { Boosting, } \\
\text { Decision Tree, } \\
\text { Health care, ML, } \\
\text { Stress Prediction } \\
\text { and begging. }\end{array}$ \\
\hline $\begin{array}{l}\text { Supporting the } \\
\text { Treatment of Mental } \\
\text { Diseases using Data } \\
\text { Mining }\end{array}$ & $\begin{array}{l}\text { Shahidul Islam } \\
\text { Khan et al.[30] }\end{array}$ & $\begin{array}{ll}\text { Random } & \text { Forest, } \\
\text { SVM, KNN } & \end{array}$ & $\begin{array}{l}\text { Collected from } \\
\text { NIMH Hospital's } \\
\text { report description in } \\
\text { Bangladesh }\end{array}$ & $\begin{array}{l}\text { Anxiety and } \\
\text { psychosis }\end{array}$ & $\begin{array}{l}\text { Classification } \\
\text { Algorithm, Data } \\
\text { Mining, Mental } \\
\text { Disease, Health } \\
\text { record. }\end{array}$ \\
\hline $\begin{array}{l}\text { A system to detect } \\
\text { mental stress using } \\
\text { machine learning } \\
\text { and mobile } \\
\text { development }\end{array}$ & $\begin{array}{l}\text { Chandrasekhar } \\
\text { Vuppalapat } \\
\text { Et al.[23] }\end{array}$ & SVM, KNN & $\begin{array}{l}\text { Tweet text and } \\
\text { representations in } \\
\text { the form of images, } \\
\text { comments on visual } \\
\text { attributes of tweets }\end{array}$ & Stress & $\begin{array}{l}\text { EEG Biosensors, } \\
\text { ML, Mental stress } \\
\text { Mobile } \\
\text { Development, } \\
\text { Health care, } \\
\text { SVM, KNN, } \\
\text { Mind wave }\end{array}$ \\
\hline $\begin{array}{lr}\text { Intelligent } & \text { health } \\
\text { risk } & \text { prediction } \\
\text { systems } & \text { using } \\
\text { machine learning: A } \\
\text { review }\end{array}$ & $\begin{array}{l}\text { Mr. Santosh A. } \\
\text { Shinde et } \\
\text { al.[17] }\end{array}$ & AD Tree and KNN & $\begin{array}{l}\text { Data from social } \\
\text { networking sites }\end{array}$ & $\begin{array}{l}\text { Psychological } \\
\text { condition }\end{array}$ & $\begin{array}{l}\text { Electronic health } \\
\text { records, health } \\
\text { risk predictions, } \\
\text { ML }\end{array}$ \\
\hline
\end{tabular}

\section{Future Challenges in Mental Health Detection}

The mental health disorder is difficult to categories because various feature selection processes are implemented by Researchers which is a major challenge in this study. The quality of dataset and its interpretation is a challenge. The data collected from the various devices should be very accurate and precise. Imprecise data from devices will lead to failure of the proposed system. The security, Privacy and ethical issues are important challenges in this field. To avoid issues related to privacy, safety precautions need to be taken, such as user authentication mechanisms and encryption of data.

The information available in Online Social Networks

[22] provides a huge or bulk of data having immense potential that is to be explored in modern research. For this we extract millions of data to understand the phenomenon selected for a study. The researchers focused on detection of mental health problem through several findings to be referred by researchers for futurestudies. i) Initially few studies on mental health are found very informative like people with this disorder isolates themselves do not communicates with other peoples. They are quite simple and do not interact easily. Their social life is not normal as compared with non-stressed people. [28]. It's a challenges to make them feel that they are also normal humans.

ii) People with depression are involved in negative emotions and religious judgements [14]. They are involved in their own self.

iii) The major challenge is of language barriers as they use different languages in mental health problem detection. During data analytics, in Online Social Networks it was diagnosed that people with depression behaves differently on various situations [22].

iv)Detection of Mental health involves several challenges in non-face-to-face communication andhuman computer interaction [22].

v)The use of machine learning(ML) can help them to understand and determine the possibility of an 
existing mental health state behind the words and languages in [14].

vi) The Privacy and security policies are the challenges faced by many researchers during their data preparation as due to the collection of public user data, such as those collecting from Twitter.

Some of these Challenges are summarized as follows:

- The Quality and interpretation of data set andmodal.

- Detection of mental health with time.

- Multiple categories of mental healthproblems.

- Preprocessing of data.

- Data quantity and generalizability.

- Data sparsity and ethical code.

\section{Conclusion:}

This review paper concludes that if the clinical heterogeneity of the samples of patient's data having bipolar disorder is given then by using machine learning techniques will provide researchers and clinicians with great insights in the fields such as diagnosis of diseases, their personalized treatment and prognosis orientation. Machine learning techniques for the prediction of stress and mental health condition will gives significant response and this can be studied and explored for further research objectives. Over the time, if we do not control the emotional conditions, anxiety will become worse day by day and turns into a pathological situations and that is quite challenging to treat. These mental health disorders result in harm to the human body as it leads to suppression of theimmune system, which then increases the chance of susceptibility to various infectious diseases, increase in blood pressure, and diabetes.

\section{References:}

[1]. S, Vinitha and S, Sweetlin and H, Vinusha and S, Sajini, Disease Prediction Using MachineLearning Over Big Data (February 2018). Computer Science \& Engineering: An International Journal (CSEIJ), Vol.8, No.1, February 2018, Available //dx.doi.org/10.2139/ssrn.34587751

[2]. Axel Junestrand Leal (2018); Application of Machine Learning Algorithms for Bipolar Disorder Crisis

Prediction;

Leal2018ApplicationOM

[3] Sau, Arkaprabha \& Bhakta, Ishita. (2017). Predicting anxiety and depression in elderly patients using machine learning technology. Healthcare Technology

Letters. 10.1049/htl.2016.0096.

[4] Maggiotti, Gabriel. (2018). Automated

BrainDisorders Diagnosis through Deep NeuralNetworks.

@ article\{Maggiotti2019AutomatedBD, title $=\{$ Automated Brain Disorders

DiagnosisThrough Deep Neural

Networks $\}$, author $=\{$ Gabriel A.

Maggiotti $\}$,journal $=\{$ viXra $\}$, year $=\{2019\}\}$

[5]. Doryab, A., Frost, M., Faurholt-Jepsen, M. et al. Impact factor analysis: combining prediction with parameter ranking to reveal the impact of behavior on health outcome. Pers UbiquitComput 19, 355-365(2015). https://doi.org/10.1007/s00779-014-0826-8

[6]. Grünerbl et al., Smart-Phone Based Recognition of States and State Changes in Bipolar Disorder Patients, vol. 19, IEEE Journal of Biomedical and Health Informatics, 2014.

[7]. Nicholas J, Larsen ME, Proudfoot J, Christensen

H. Mobile Apps for Bipolar Disorder: A Systematic Review of Features and Content Quality. J Med Internet Res. 2015 Aug 17;17(8):e198. doi: 10.2196/jmir.4581. PMID: 26283290; PMCID: PMC4642376.

[8]. Faurholt-Jepsen, M., Bauer, M. \& Kessing, L.V. Smartphone-based objective monitoring in bipolar disorder: status and considerations. Int $J$

Bipolar Disord 6, 6 https://doi.org/10.1186/s40345-017-0110-8

[9]. auer, Michael \& Grof, Paul \& Rasgon, Natalie \& Glenn, Tasha \& Alda, Martin \& Priebe, Stefan \& Ricken, Roland \& Whybrow, Peter. (2006). MoodCharting and Technology: New Approach to Monitoring Patients with Mood Disorders. Current Psychiatry Reviews. 2. 423-429. 10.2174/157340006778699747.

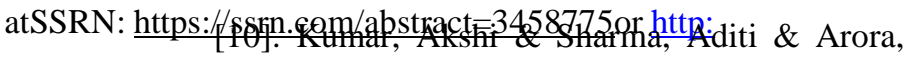
Anshika. (2019). Anxious Depression Prediction in Real-time Social Data.

[11]. Detecting depression using machine learning: Ezekiel Victor a Zahra M. Aghajan, Ph.D. b;Amy R. Sewart, M.A., C.Phil c;Ray Christian.,B.B.A.AiMEResearchPaper_forSu bmission_PsyArXiv.pdf Version: 1Created: October $\quad 01, \quad 2018$ | Last edited: December 25, 2018 
[12]. Pintelas, Emmanuel \& Kotsilieris, Theodore \& Livieris, Ioannis \& Pintelas, P.. (2018). A review of machine learning prediction methods for anxiety disorders. $10.1145 / 3218585.3218587$.

[13]. Islam MR, Kabir MA, Ahmed A, Kamal ARM, Wang H, Ulhaq A. Depression detection from social network data using machine learning techniques. Health Inf Sci Syst. 2018 Aug 27;6(1):8. doi: 10.1007/s13755-018-0046-0. PMID: 30186594; PMCID: PMC6111060.

[14]. Shatte ABR, Hutchinson DM, Teague SJ. Machine learning in mental health: a scoping review of methods and applications. Psychol Med. 2019 Jul;49(9):1426-1448. doi: 10.1017/S0033291719000151. Epub 2019 Feb

\section{PMID: 30744717.}

[15]. Portugal LCL, Schrouff J, Stiffler R, Bertocci M,Bebko G, Chase H, Lockovitch J, Aslam H, Graur S, Greenberg T, Pereira M, Oliveira L, Phillips M, Mourão-Miranda J. Predicting anxiety from wholebrain activity patterns to emotional faces in young adults: a machine learning approach. Neuroimage Clin. 2019;23:101813. doi: 10.1016/j.nicl.2019.101813. Epub 2019 Apr 3.

PMID: 31082774; PMCID: PMC6517640

[16]. Martínez, A.; Benítez, R.; Estrada, H.; Hernández, Y. Predictive Model for Detection ofDepression Based on Uncertainty Analysis Methods. Proceedings 2018, 2, 551.

[17]. SANTOSH A. SHINDE, Mr; P. RAJA

RAJESWARI, Dr. Intelligent health risk prediction systems using machine learning: a

review. International Journal of Engineering \& Technology, [S.1.], v. 7, n. 3, p. 1019-1023, june 2018. ISSN 2227524X. Available at: <https://www.sciencepubco.com/index.php/ij et/a rticle/view/12654/5965>. Date accessed: 23 nov. 2020.

doi:http://dx.doi.org/10.14419/ijet.v7i3.12654

[18]. .Librenza-Garcia, Diego \& Kotzian, Bruno \& Yang, Jessica \& Mwangi, Benson \& Cao, Bo \& Lima, Luiza \& Bagatin Bermudez, Mariane \& Boeira, Manuela \& Kapczinski, Flavio \& Passos, Ives. (2017). The impact of machine learning techniques in the study of bipolar disorder: A systematic review.
Neuroscience \& Biobehaviora Reviews.

80.

10.1016/j.neubiorev.2017.07.004.

[19]. Lee, Heon-Jeong \& Cho, Chul-Hyun \& Lee, Taek \& Kim, Min-Gwan \& In, Hoh \&

Kim, Leen.(2018). Mood prediction of patients with mood disorder by machine learning using passive digitalphenotypes based on circadian rhythm: a prospective observational cohort study (Preprint).Journal of Medical Internet Research. 21.

10.2196/11029.

[20]. Q. Sun and Qixuan Yue and F. Zhu and Kunxian Shu (2019); The Identification research of bipolar disorder based on $\mathrm{CNN}$; Sun2019TheIR

[21]. R. Jadhav, V. Chellwani, S. Deshmukh and H. Sachdev, "Mental Disorder Detection : Bipolar Disorder Scrutinization Using Machine Learning," 2019 9th International Conference on Cloud Computing, Data Science \& Engineering (Confluence), Noida, India, 2019, pp. 304-308, doi: 10.1109/CONFLUENCE.2019.8776913.

[22]. Abd Rahman, Rohizah \& Omar, Khairuddin \& Mohd Noah, Shahrul Azman \& Mohd Danuri, Mohd Shahrul Nizam \& Al-Garadi, Mohammed. (2020). Application of Machine Learning Methods in Mental Health Detection: A Systematic Review. IEEE Access. 8. 183952183964. 10.1109/ACCESS.2020.3029154.

[23]. A. Khattar, P. R. Jain and S. M. K. Quadri, "Effects of the Disastrous Pandemic COVID 19 on Learning Styles, Activities and Mental Health of Young Indian Students - A Machine Learning Approach," 2020 4th International Conference on Intelligent Computing and Control Systems (ICICCS), Madurai, India, 2020, pp. 1190-1195, doi: 10.1109/ICICCS48265.2020.9120955.

[24]. C. Vuppalapati, M. S. khan, N. Raghu, P. Veluru and S. Khursheed, "A System To Detect Mental Stress Using Machine Learning And Mobile Development," 2018 International Conference on Machine Learning and Cybernetics (ICMLC), Chengdu, 2018, pp. 161-166, doi: 10.1109/ICMLC.2018.8527004.

[25]. P. V. Narayanrao and P. Lalitha Surya Kumari, "Analysis of Machine Learning Algorithms for Predicting Depression," 2020 International Conference on Computer Science, Engineering and Applications (ICCSEA), Gunupur, India, 2020,

pp. $\quad 1-4$ 
[26]. E. Gore and S. Rathi, "Surveying Machine Learning Algorithms On Eeg Signals Data For Mental Health Assessment," 2019 IEEE Pune Section International Conference (PuneCon), Pune, India, 2019, pp. 1-6, doi: 10.1109/PuneCon46936.2019.9105749.

[27]. A. Khattar, P. R. Jain and S. M. K. Quadri, "Effects of the Disastrous Pandemic COVID 19 on Learning Styles, Activities and Mental Healthof Young Indian Students - A Machine Learning Approach," 2020 4th International Conference on Intelligent Computing and Control Systems (ICICCS), Madurai, India, 2020, pp. 1190-1195, doi: 10.1109/ICICCS48265.2020.9120955.

[28]. N. S. Alghamdi, "Monitoring Mental Health Using Smart Devices with Text Analytical Tool," 2019 6th International Conference on Control, Decision and Information Technologies (CoDIT), Paris, France, 2019, pp. 2046-2051, doi: 10.1109/CoDIT.2019.8820381.

[29]. U. S. Reddy, A. V. Thota and A. Dharun, "Machine Learning Techniques for Stress , doi: 10.1109/ICISET.2018.8745591.
Prediction in Working Employees," 2018

IEEE International Conference on Computational Intelligence and Computing Research (ICCIC), Madurai, India, 2018, pp. 1-4, doi: 10.1109/ICCIC.2018.8782395.

[30]. V. Mody and V. Mody, "Mental Health Monitoring System using Artificial Intelligence: A Review," 2019 IEEE 5th International Conference for Convergence in Technology (I2CT), Bombay, India, 2019, pp. 1-6, doi: 10.1109/I2CT45611.2019.9033652.

[31]. S. I. Khan, A. Islam, A. Hossen, T. I. Zahangir and A. S. M. Latiful Hoque, "Supporting the Treatment of Mental Diseases using Data Mining," 2018 International Conference on Innovations in Science, Engineering and Technology (ICISET), Chittagong, Bangladesh, 2018, pp. 339-344

[32]. Gitlin, M., Malhi, G.S. The existential crisis of bipolar II disorder. Int $J$ Bipolar Disord 8, 5(2020).https://doi.org/10.1186/s 40345-019-0175-7 